\title{
Relation between indicators for quality of occupational rehabilitation of employees with low back pain
}

\author{
Willeke E van der Weide, Jos H A M Verbeek, F J H van Dijk
}

\begin{abstract}
Objectives-To assess if the implementation of guidelines for occupational rehabilitation of patients with low back pain by means of process variables-a set of objective criteria for technical performance and continuity of care-led to a better outcome in clinical and return to work variables.

Methods-The study group consisted of 59 patients with at least 10 days of sick leave because of low back pain. Univariate analyses as well as multiple logistic regression and Cox's regression analyses were performed to assess the relation between quality of care and outcome.

Results-Process indicators for technical competence, continuity of care, and total performance were all significantly related to satisfaction of employees. Continuity of care and total performance were significantly related to working status at 3 months, and time to return to work. None of the process indicators was related to pain or disability after 3 months follow up. Satisfaction was not related to any of the other outcome variables. This indicates that if guidelines for occupational rehabilitation are met, outcome is better.

Conclusion-Quality of the process of care was related to outcome. Interventions of occupational physicians need improvement in the areas of continuity of care and communication with treating physicians. The effectiveness of an improved intervention should be studied in a subsequent randomised clinical trial.

(Occup Environ Med 1999;56:488-493)
\end{abstract}

Keywords: occupational rehabilitation; quality of care; low back pain

Occupational physicians in The Netherlands spend almost half of their time on matters concerned with sickness absence and rehabilitation activities, especially during consultation hours. ${ }^{12}$ The goal of these activities is to restrict occupational disability and duration of sick leave by searching for a balance between workload and work ability. ${ }^{3}$ Recently, quality assessment of these and other tasks of occupational health care professionals has become more important. Because of the increased demands for cost effectiveness, an occupational health service has to justify the value of all medical services that it provides to companies and their employees. Besides, occupational health services are legally obliged to certify fulfillment of criteria for "good quality", in the Netherlands. Although this certification process is mainly directed at the quality system of the occupational health service, an assessment of the professional content of care should be incorporated in this system. ${ }^{4}$ Viewed in this light, it is important to trace deviations from "good quality" to enable improvements. ${ }^{5}{ }^{6}$

However, the evaluation of occupational rehabilitation is complicated. The desired outcome - that is, a decrease of disability and sick leave - is not only dependent on the process that can be managed by the occupational physician. Other variables-such as the seriousness of the employee's disability, regulations in the company, availability of light work, etcinfluence the process of return to work. Therefore, it is inadequate to assess quality of occupational rehabilitation by its outcome only. Process variables could provide a more sensitive estimator of quality than outcome. ${ }^{7}$ It is therefore important to investigate the relation between process and outcome. ${ }^{8}$ We were interested in investigating this relation with a randomised clinical trial about the efficacy of occupational rehabilitation for patients with low back pain (unpublished data).

For the assessment of the process of occupational rehabilitation we first had to define "good practice". We developed and implemented guidelines among occupational physicians. ${ }^{9}$ Ideally, these guidelines should be evidence-based, but evidence was not available for all aspects. Therefore, various parts of the guidelines were based on the opinions of experts. ${ }^{10}$ As variables for the quality of the process a set of objective criteria for seven performance indicators, representing technical performance and continuity of care were derived from the guidelines. ${ }^{11}$

As another potential variable of quality assessment we measured satisfaction of the employee. An advantage of measuring satisfaction is that a questionnaire can contain aspects other than technical care-such as relational, organisational, and financial aspects. In the patient's view of quality the relational aspects seem more important than the other two. ${ }^{12}$ Another potential advantage of measuring satisfaction as a variable of quality is related to the effectiveness of care. Satisfaction has been shown to positively influence patients' adherence to therapeutic recommendations. ${ }^{13}$ In occupational rehabilitation this relation has never been investigated. 
In this paper, we have studied the relation between process and outcome variables. In this way explanations for differences in outcome can be discovered. We measured the following outcome variables: patient satisfaction with the occupational rehabilitation process, intensity of pain, functional disability, rate of return to work at 3 months, and time to return to work.

\section{Methods}

STUDY POPULATION

The study group consisted of 59 employees who visited their occupational physician because of sick leave with low back pain. It is a subgroup of employees who were recruited into the active arm of a randomised trial among 120 employees in eight occupational health services for hospital and university employees. Within 2 weeks after reporting sick with low back pain, the employees were asked to participate in the study. Of these employees $15 \%$ refused to participate. The employees who refused to participate did not differ significantly from those who participated in sex, age, occupation, return to work, or sick leave for a period of 1 year. After giving informed consent the employees were randomly assigned to a group actively rehabilitated by an occupational physician or to a reference group. The group with the occupational physician did not differ significantly $(\mathrm{p}<0.05)$ from the other participants in the trial in demographic factors, perception of working conditions, characteristics related to low back pain, psychosocial characteristics (except palliative coping reactions, which were lower among this study group, $\mathrm{p}=0.03$ ), pain, functional disability at baseline and after 3 months, rate of return to work at 3 months, and time to return to work. In the group with an occupational physician $(n=61)$ the employees were invited for the consultation as soon as possible after inclusion in the study. From that group 59 employees visited their occupational physician because of low back pain during the first 3 months. Two employees did not (one because the occupational physician's appointment schedule was full, the other because the primary diagnosis was changed). Therefore, the group for this study consisted of 59 employees.

\section{DATA COLLECTION}

The employees received a questionnaire at baseline about demographic factors, perception of working conditions, ${ }^{14}$ characteristics of low back pain, intensity of pain, ${ }^{15}$ functional disability, ${ }^{16}{ }^{17}$ general health perception, ${ }^{18}$ coping, ${ }^{19}$ and health locus of control. ${ }^{20}$ Pain intensity during the week before measurement was assessed on a $100 \mathrm{~mm}$ line, ranging from no pain to very severe pain. ${ }^{15}$ The Roland disability questionnaire (RDQ) was used to assess functional disability. It has been reported to be a reliable, valid, and responsive instrument. ${ }^{21} 22$ The RDQ contains 24 yes or no questions. The total score can range from 0 to 24 and we transformed this to a 0-100 range. Scores on the scales for perception of working conditions were also expressed on a 0-100 continuum.
Coping and health locus of control were dichotomised: problematic cases were defined as those above the 75 th percentile score.

Every month the participant noted whether he or she had returned to work, with or without adaptations. Return to work was also determined from computerised record systems. Duration of sick leave was measured over a 1 year period. After 3 months data were collected from questionnaires on patient satisfaction with occupational rehabilitation and again on pain and functional disability. The patient satisfaction questionnaire consisted of 24 statements about several aspects (communication, interpersonal approach, professional knowledge, usefulness) with a five point rating scale, from totally agree to totally disagree. Thirteen questions were formulated positively and 11 negatively to prevent a trend in answering. ${ }^{23} \mathrm{~A}$ total score was calculated by summarising the items and assuming an interval scale. The total score was expressed on a scale from 0 (very dissatisfied) to 100 (very satisfied). The questionnaire had a high internal consistency as reflected by a Cronbach's $\alpha$ for the completed questionnaire of 0.96 and a mean (SD) corrected item total correlation of 0.68 (0.14). The SD was around 1.0 scale point for most items and never below 0.65 , indicating a range of opinions for all statements.

The occupational physicians were instructed about the guidelines for occupational rehabilitation of patients with low back pain in two meetings before the trial, and in follow up meetings during the research period. During the first 3 months the occupational physician registered his or her activities in occupational rehabilitation on a special form for each participant when the employee came to the consultation. This form was used to derive data for the calculation of performance indicators for each patient.

\section{PROCESS AND OUTCOME VARIABLES}

On the basis of the guidelines for occupational rehabilitation we defined seven performance indicators with explicit criteria for good or deviant performance of the occupational physician for specific rehabilitation activities. ${ }^{11}$ The criteria for each performance indicator were formulated in "if then" statements - the so called "criteria mapping" 24 or "branching logic" method. ${ }^{26}$ Each statement could be met, be deviant, or be inapplicable. Performance for an indicator deviated from the guidelines if one or more of the criteria for that indicator were not met. Six indicators reflect the various areas in the guidelines: encouragement of activity, assessment and action for psychosocial problems, curative treatment, the work site, the work organisation, and advice on returning to work. These six indicators were summarised in a performance score for the technical competence of the occupational physician and differentiated in a $0-1$ score $(0=$ no deviance in any of the six indicators, $1=$ deviant in at least one indicator). The seventh indicator reflected continuity of care. This indicator can also be met, not met (deviant), or not applicable. Total performance was assessed as a summary of 
Table 1 Physician performance indicators (PIs) and criteria for good performance for rehabilitation of workers with low back pain

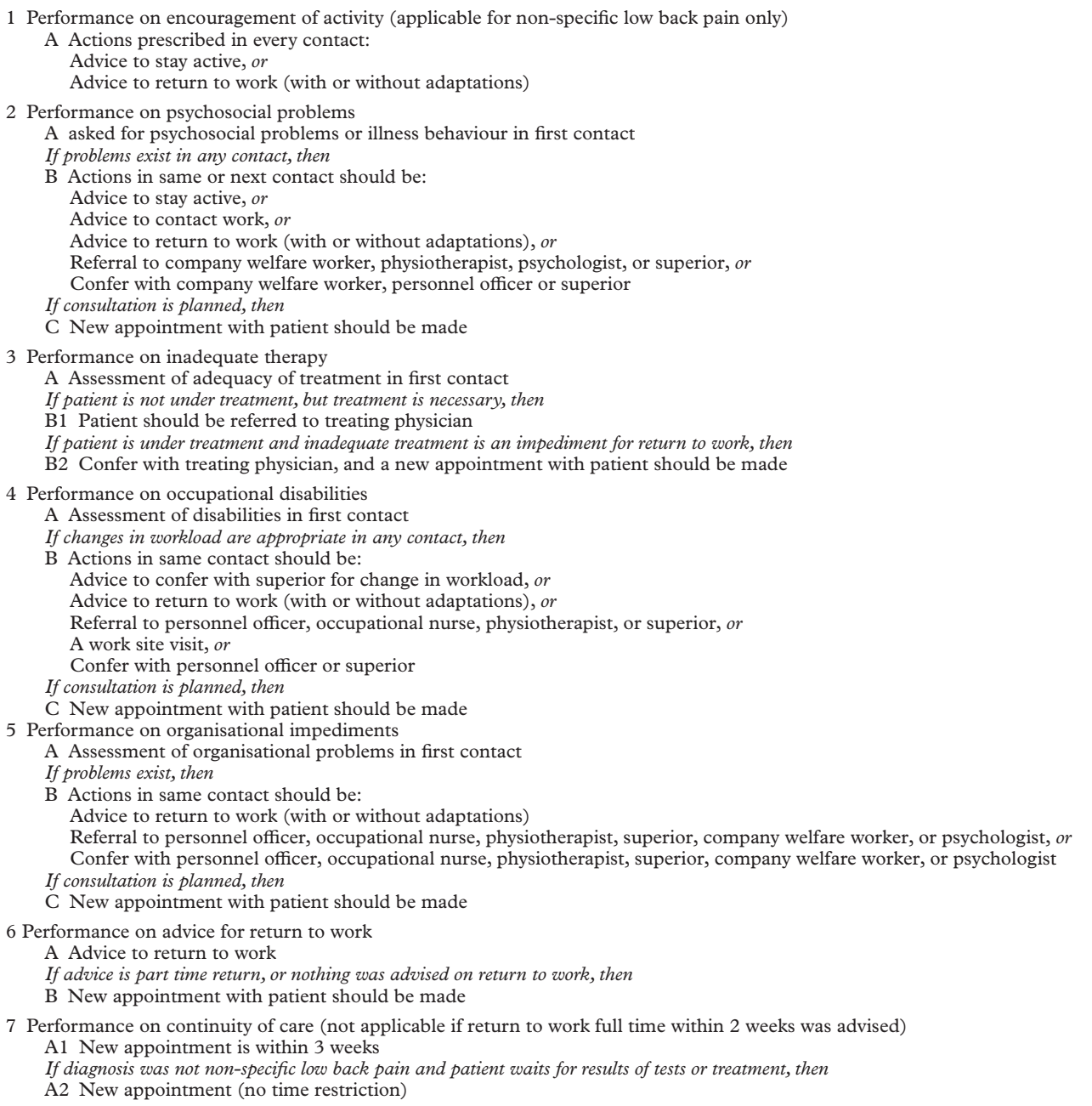

both scores and was also dichotomised in a $0-1$ score. In table 1 the criteria for the seven performance indicators are presented.

Patient satisfaction with the occupational rehabilitation process, pain intensity, and functional disability at 3 months of follow up were used as outcome measures. For outcome variables about absence from work we used the rate of return to work at 3 months and time to return to work. The dependent variables were blindly administered, so without knowledge of the process variables and prognostic factors.

\section{STATISTICAL ANALYSIS}

The relations between performance scores and prognostic factors on the one hand and satisfaction and return to work variables on the other hand were tested, firstly in a univariate way and subsequently in a multivariate model. In the univariate analyses $\chi^{2}$ tests were performed to analyse relations between two discrete variables and $t$ tests for continuous variables with normal distributions, or otherwise with the Mann-Whitney $U$ test. To study the relation between performance and the outcome time to return to work, Cox's regression survival curves were assessed for the groups with and without deviant performance scores.
The performance scores for technical competence were constructed on the basis of an assumed relation between a deviant score on every indicator and outcome of care. However, it is possible that some indicators did not contribute to this relation and that the analysis with this totalled score concealed real relations between the separate indicators and outcome. Therefore, we also performed analyses for the separate performance indicators with $\geqslant 15 \%$ deviant scores (encouragement of activity and inadequate treatment).

For the multivariate analyses, the performance scores as well as other prognostic factors were included. To reduce the number of variables in the multivariate analysis only those prognostic factors that were related to the outcome in the univariate analysis $(\mathrm{p}<0.15)$ were included in the model. The selection of variables for entry into the model in the manual forward stepwise selection procedure $\left(\mathrm{p}_{\text {in }}<0.05 ; \mathrm{p}_{\text {out }}>0.10\right)$ was based on statistical reasoning as well as on practical relevancy to the work of an occupational physician The following prognostic factors were entered into the model with patient satisfaction as the outcome: work speed and work quantity, lack of variation in work, social isolation, duration before first 
Table 2 Characteristics of study population at baseline $(n=59)$

\begin{tabular}{lrc}
\hline Patient characteristics: & & \\
Mean (SD) age (y) & 38 & $(7.9)$ \\
Sex (male, $\mathrm{n}(\%)$ ) & 23 & $(39)$ \\
Low back pain related characteristics: & & \\
Diagnosis at first consultation (n (\%)): & 46 & $(78)$ \\
$\quad$ Non-specific low back pain & 12 & $(20)$ \\
Nerve root compression & 1 & $(2)$ \\
$\quad$ Unclear & 18 & $(31)$ \\
History of low back pain: & 23 & $(40)$ \\
Sick leave last year (n (\%) yes) & 19 & $(33)$ \\
Sick leave ever (n (\%) more than once) & 28 & $(16)$ \\
Work related cause of low back pain (n (\%)) & 56 & $(22)$ \\
Duration of sick leave at first consultation (mean (SD)) & 57 & $(21)$ \\
Mean (SD) pain intensity & & \\
Mean (SD) functional disability & 16 & $(27)$ \\
Work related characteristics: & 31 & $(53)$ \\
Occupation (n (\%)): & 12 & $(20)$ \\
Mentally demanding work & $8.9(34)$ \\
Mixed mentally and physically demanding work & & \\
Light physically demanding work & 24 & $(42)$ \\
Mean (SD) working hours & 15 & $(25)$ \\
Work experience in present position(y, $n(\%)):$ & 20 & $(34)$ \\
$\quad<5$ &
\end{tabular}

Table 3 Care (from baseline to 3 months) and outcome characteristics of the study population $(n=59)$

\begin{tabular}{ll}
\hline Care characteristics: & \\
Number of contacts with the occupational physician/patient (n (\%)): & $20(34)$ \\
1 & $14(24)$ \\
2 & $25(42)$ \\
$>2$ & $24(49)$ \\
Performance indicators (n (\%) deviant): & $22(38)$ \\
$\quad$ Continuity of care & $36(62)$ \\
Technical competence (sum of 6 indicators) & \\
$\quad$ Total performance (sum of 7 indicators) & $18(36)$ \\
Work adaptations at return to work (n (\%)): & $37(70)$ \\
In tasks & $21(44)$ \\
In working hours & $2(4)$ \\
In work tempo & $41(77)$ \\
$\quad$ Mechanical) devices & \\
Any adaptation & $66(16)$ \\
Outcome variables: & $31(25)$ \\
Patient's satisfaction (mean (SD)) & $26(23)$ \\
Pain intensity at 3 months (mean (SD)) & \\
Functional disability at 3 months (mean (SD)) & $40(68)$ \\
Return to work status at 3 months (n (\%)): & $16(27)$ \\
Full time returned & $3(5)$ \\
Part time returned & $51(22-112)$ \\
Not returned & \\
Time to return to work (median (interquartile ranges)) & \\
\hline
\end{tabular}

Table 4 Relation between performance indicators (not deviant $v$ deviant score) and outcome variables (satisfaction score 0-100, percentage of workers not returned to work at three months, days off work) $t$

\begin{tabular}{|c|c|c|c|}
\hline Performance indicator & Not deviant score & Deviant score & Mean difference $(95 \% \mathrm{CI})$ \\
\hline \multicolumn{4}{|c|}{ Patient satisfaction (mean (SD)): } \\
\hline Continuity of care & $71(11)$ & $59(11)$ & $12(2.0 \text { to } 22)^{\star}$ \\
\hline Technical competence & $71(14)$ & $58(17)$ & $13(3.5 \text { to } 22)^{\star \star}$ \\
\hline Total performance & $73(11)$ & $62(18)$ & $11(2.5 \text { to } 20)^{\star}$ \\
\hline \multicolumn{3}{|c|}{ No full time return to work $(\%(n))$ : } & Odds ratio $(95 \% \mathrm{CI})$ \\
\hline Continuity of care & $20(5)$ & $58(14)$ & $5.6(1.6 \text { to } 20)^{\star \star}$ \\
\hline Technical competence & $33(12)$ & $32(7)$ & $0.93(0.30$ to 2.9$)$ \\
\hline Total performance & $14(3)$ & $44(16)$ & $5.1(1.3 \text { to } 20)^{\star}$ \\
\hline \multicolumn{3}{|c|}{ Time to full time return to work (median (interquartile range)): } & Hazard ratio $(95 \%$ CI) \\
\hline Continuity of care & $34(25$ to 64$)$ & 95 (59 to 168$)$ & $0.47(0.26 \text { to } 0.86)^{\star \star}$ \\
\hline Technical competence & $32(12$ to 99$)$ & $59(47$ to 131$)$ & $0.74(0.42$ to 1.3$)$ \\
\hline Total performance & $21(11$ to 32$)$ & $77(48$ to 131$)$ & $0.43(0.24 \text { to } 0.75)^{\star \star}$ \\
\hline
\end{tabular}

${ }^{\star} \mathrm{p}<0.05 ;{ }^{\star \star} \mathrm{p}<0.01$.

tThe analyses of the relation between performance scores on the one hand and satisfaction and outcome on the other hand were performed with different numbers of patients, depending on the outcome parameter. cian, pain at baseline, functional disability at baseline, radiating pain, and the coping scale palliative reactions were entered into the model.

To get more meaningful results for satisfaction we divided the group into patients with scores up to the 25 th percentile representing dissatisfied patients, and patients with scores above this point, satisfied patients. Prognostic factors with a non-normal distribution were divided into two subgroups, with the 75 th percentile as a cut off point, and were treated as discrete variables. All analyses were done with SPSS for windows 6.1.3 (SPSS, Illinois, USA).

\section{Results}

PATIENT, CARE, AND OUTCOME CHARACTERISTICS The patient characteristics of the study group are summarised in table 2 . The care characteristics (from baseline to 3 months) and outcome variables are presented in table 3 . One third of the patients had one contact with the occupational physician, more than $40 \%$ had three or more contacts. We did not receive a registration form about one employee, so the performance scores are the scores of 58 patients. The performance scores for technical competence deviated for $38 \%$ of the cases and for continuity of care for $49 \%$. The separate performance indicators encouragement of activity and inadequate treatment deviated most often (15\% and $17 \%)$. The other separate indicators, which together constituted the technical competence score, deviated at most in four cases.

At three months $68 \%$ of the patients were fully recovered from the first episode, and $27 \%$ worked part time. Seventy seven per cent returned to work with some kind of adaptation, mostly in working hours $(70 \%)$. Pain and disability were about halved compared with the start of the trial. Median duration of sick leave of the first episode until the end of follow up was 51 days (interquartile ranges 22-112). Forty eight patients responded to the satisfaction questionnaire $(81 \%)$. The mean (SD) of the total satisfaction score was 66 (16).

PERFORMANCE INDICATORS AND OUTCOME Performance for technical competence, continuity of care, and total performance were all significantly related to patient satisfaction in the univariate analysis (table 4). Of the separate performance indicators for technical competence only, inadequate treatment was marginally related to patient satisfaction.

Table 5 presents the significant results of the complete multiple logistic regression model with patient satisfaction as the dependent variable. A higher risk of dissatisfaction was found when patients had a deviant technical competence score (odds ratio (OR) 9.3, 95\% confidence interval ( $95 \% \mathrm{CI}$ ) 1.2 to 71 ), a deviant continuity of care score (OR 10.4, 95\% CI 1.4 to 75 ), or a work related cause (OR 2.1, $95 \%$ CI 1.1 to 60 ).

Continuity of care and total performance were significantly related to work at 3 months, and to time to return to work (table 4). Of the separate performance indicators only a deviant score on inadequate treatment was significantly 
Table 5 Multiple logistic regression to explain dissatisfaction of low back pain patients $(n=42)$, not returned to full time to work at 3 months $(n=48)$, and Cox's regression analysis to explain time to return to full time to work $(n=47)$ *

\begin{tabular}{lcl}
\hline & Odds ratio & $95 \% C I$ \\
\hline Dissatisfaction: & & \\
Deviant technical competence & 9.3 & 1.2 to 71 \\
Deviant continuity of care & 10.4 & 1.4 to 75 \\
$\quad$ Work related cause of low back pain & 8.1 & 1.1 to 60 \\
Not working full time at 3 months: & 11.8 & 2.0 to 71 \\
Deviant continuity of care & 1.05 & 1.0 to 1.1 \\
Functional disability at baselinet & 8.7 & 1.1 to 41 \\
Social isolation & Hazard ratio & $95 \% C I$ \\
Time to full time return to work: & 0.41 & 0.20 to 0.81 \\
Deviant continuity of care & 0.32 & 0.16 to 0.63 \\
Radiating pain until or below knee & 0.97 & 0.96 to 0.99 \\
Functional disability at baseline† & & \\
\hline
\end{tabular}

${ }^{\star}$ Univariate prognostic factors at baseline with $\mathrm{p}<0.15$ (perception of working conditions, characteristics related to low back pain, and psychosocial characteristics) were also entered into the multivariate model. This table only presents statistical significant results.

†Continuous variable with ranges $0-100$.

related to time to return to work. The figure shows longer times to return to work among those patients with deviant total performance scores. In the multivariate analyses, not working full time after 3 months was mainly explained by deviant continuity of care (OR 12, $95 \%$ CI 2.0 to 71 ), high disability at baseline (OR 1.05, 95\% CI 1.0 to 1.1 ), and social isolation at baseline (OR 6.7, 95\% CI 1.1 to 41 , table 5). Also, the time to return to work was substantially longer among patients with deviant continuity of care scores as reflected by a hazard ratio of 0.41 (95\% CI 0.20 to 0.81 ), high disability at baseline (hazard ratio 0.97 , $95 \%$ CI 0.96 to 0.99 ), and radiating pain (hazard ratio $0.32,95 \%$ CI 0.16 to 0.63 ). A hazard ratio $<1$ indicates that the variable is associated with a longer time to return to work. For instance, a hazard ratio of 0.41 means that the estimated risk of return to work is 0.41 for patients with deviant continuity of care, compared with a person with a non-deviant score. In other words, the chance of return to work is 2.4 higher for patients with a non-deviant score.

Satisfaction of the employee was not related to one of the other outcome variables.

\section{Discussion}

In this study of the process and outcome of occupational rehabilitation we found devia-

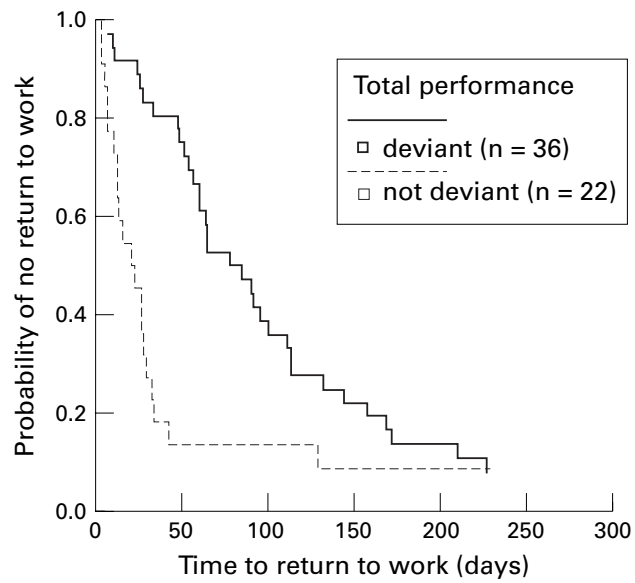

Cumulative probability of no return to work relative to total performance. None of the performance indicators was related to pain or disability after 3 months follow up. tions in performance of occupational physicians especially in encouragement of activity, inadequate treatment, and continuity of care. Inadequate treatment, continuity of care, and the total performance score were related to the outcome variables patient satisfaction, rate of return to work, and time to return to work.

Potential prognostic factors could bias the results. More serious cases could have a higher risk of both a poor outcome and a deviant performance because it could be more difficult to meet the criteria for performance with these cases. To control for these prognostic factors we performed a multivariate analysis. Only a work related cause, functional disability at baseline, social isolation, and radiating pain were significantly related to the outcome in these models, but performance also remained a significant predictor of outcome. So we could not show that our results were biased by any of the prognostic factors that we could measure.

Another source of bias is the derivation of criteria for the performance indicators from the guidelines. Our criteria for the prescribed actions were formulated broadly, resulting in only a loose definition of deviance. The not deviant group included those cases that also could be qualified as deviant with a more strict definition. However, without this nondifferential misclassification the relation would even have been stronger.

This study indicates that contact with the treating physician - that is, a criterion for good performance in adequate treatment-or a follow up every 3 weeks - that is, a criterion for good continuity of care-could be effective for the deviant cases. However, a randomised trial on these aspects is needed to show the efficacy of these interventions. Other studies also indicate that the communication between occupational physician and treating physicians could be improved. ${ }^{27-29}$

It is noteworthy that we did not find a relation between performance of the occupational physician and pain or functional disability. This might reflect our lack of understanding of the return to work process in employees. It seems logical to assume that a decrease of pain and subsequently a decrease of functional disability would lead to resumption of work. However, cognitive processes such as fear of movement (because of thoughts that all movement will lead to bodily harm) and catastrophising (a way of thinking, in which all events will end in disasters) might be more important predictors of return to work as has been suggested by some authors. ${ }^{30}$ In a study on stress related complaints it was also found that there was no relation between the level of complaints and return to work. ${ }^{31}$ Therefore we advocate a more detailed study of the cognitive processes that influence return to work among patients with back pain.

Due to the low number of deviant cases it was not possible to relate all separate performance indicators to the outcome variables. It was not possible to study performance on psychosocial problems, occupational disabilities, organisational impediments for return to work, and advice for return to work. This could be a 
consequence of good compliance but also of the lack of strict criteria for these performance indicators.

It has been stated that the relation between satisfaction on the one hand and quality of care or outcome on the other hand is unclear. ${ }^{12}$ In our study also this relation was not straight forward. We did find a relation between performance indicators and patient satisfaction, but patient satisfaction was not related to return to work. By contrast with our findings, satisfaction with functional restoration programmes was found to be related to return to work in other studies. ${ }^{32}{ }^{33}$ These differences between studies probably reflect the complexity of the concept of satisfaction. More research in this field is needed; especially sick workers' expectations of occupational rehabilitation and occupational health care should be studied because these could differ from other fields of health care.

The relation between work relatedness of complaints and patient satisfaction needs to be clarified also. We found that when patients attributed the cause of back pain to work they were less satisfied with the rehabilitation of the occupational physician. This was opposite to findings of an earlier study on occupational rehabilitation in which patients were more satisfied with care if they attributed the cause of their complaints to work. ${ }^{34}$ However, in that study $^{34}$ only one contact between patient and physician was investigated and patients were not restricted to those with back pain only.

In conclusion, performance scores are useful in the assessment of quality of health care. They give important clues for improvement of the process of occupational rehabilitation. In this study we found that physician performance on adequate treatment and continuity of care were related to an increased return to work and a higher patient satisfaction. Effectiveness of improved guidelines and subsequently of improved performance on these indicators needs to be tested in a randomised trial. Such a trial should be restricted to those patients for which the criteria for performance are the same. For instance patients whose treatment is assessed as inadequate and groups with and without communication with the treating physician should be compared.

1 Docter HJ, Kuitert HDWB. Tijdsbesteding bedrijfsartsen en andere deskundigen in arbodiensten. (Spending of time of occupational physicians and other professionals in occupa-
tional health services). Tijdschrift voor Bedrijfs en Verzekeringsgeneeskunde 1996;4:203-13.

2 Smits PBA, Kroon PJ, Verbeek JHAM. Tijdsbesteding van bedriifsartsen. (Spending of time of occupational physicians). Tindschrift voor Bedrifs en Verzekeringsgeneeskunde 1996;4:9-13.

3 Buys PC, ed. Industriebond FNV, Algemene WerkgeversVereniging AWV. Sociaal-medische begeleiding. Een model voor ziekteverzuimbeleid in de praktijk. (Occupational rehabilivoor ziekteverzuimbeleid in de praktijk. (Occupational rehabilitation. A model for policy
Amsterdam: NIA, 1994 .

4 Projectbureau Certificatie Arbodiensten. Certificatietoets Arbodiensten. Structuur en methodiek in hoofdlijnen. (Structure and methods for certification of Occupational Health Services). and methods for certification of Occupational Health Services).
Den Haag: Ministerie van Sociale Zaken en WerkgelegenDen Haag:

5 hasinski AS. Evaluation of clinical practice guidelines. Can Basinski AS. Evaluation of clinical
Med Assoc $\mathcal{F} 1995 ; 153: 1575-81$.

6 Delbanco TL. Quality of care through patient's eyes. BMF 1996;313:832-3.
7 Brook RH, McGlynn EA, Cleary PD. Quality of health care. Part 2: measuring quality of care . N Engl f Med 1996;335: Part 2:

8 Donabedian A. The quality of care. How can it be assessed? FAMA 1988;260:1743-8

9 Van der Weide WE, Verbeek JHAM, Van Dijk FJH, et al. An audit of occupational health care for employees with low-back pain. Occup Med 1997;47:294-300

10 Verbeek JHAM, Van der Weide WE. Begeleiding van werknemers met lage rugklachten. (Occupational rehabilitation of employees with low back pain). In: Richtlijnen Arbozorg. Handboek voor Arbodiensten, bedriven en instellingen. Chapter BII.3.2. Den Haag: AMG/Delwel Uitgeverij BV, 1997.

11 Van der Weide WE, Verbeek JHAM, Van Dijk FJH, et al. The development and evaluation of a quality assessment instrument for occupational physicians. Occup Environ Med 1998;55:375-82.

12 Lewis JR. Patient views on quality care in general practice: literature review. Soc Sci Med 1994;39:655-70.

13 Conbere PC, McGovern P, Kochevar L, et al. Measuring satisfaction with medical case management. A quality improvement tool. American Association of Occupational Health Nurses fournal 1992;40:333-41.

14 Van Veldhoven $M$, Meijman $T$, eds. Ontwikkeling van de VBBA. In: Het meten van psychosociale arbeidsbelasting. De vragenlijst Beleving en Beoordeling van de Arbeid (VBBA). (Measurement of psychosocial work load. In: The development of the questionnaire perception and evaluation of psychosocial work). Amsterdam: NIA, 1994;71-97.

15 Linton SJ, Gotestam KG. A clinical comparison of two pain scales: correlation, remembering chronic pain, and a measure of compliance. Pain 1983;17:57-65.

16 Roland M, Morris R. A study of the natural history of low back pain. Part I. Spine 1983;8:141-4.

17 Roland M, Morris R. A study of the natural history of low back pain. Part II. Spine 1983;8:145-50.

18 Konig-Zahn C, Furer JW, Tax B. Nottingham Health Profile (NHP). In: Konig-Zahn C, Furer JW, Tax B, eds. Het meten van de gezondheidstoestand. Beschrijving en evaluatie van vravan de gezondheidstoestand. Beschrijving en evaluatie van vragenlijsten. I Algemene gezondheid. (Measurement of health sta-
tus. Description and evaluation of questionnaires. I. General tus. Description and evaluation of questionn
health). Assen: Van Gorcum, 1993;100-14.

19 Schreurs PJG, Van de Willige G, Tellegen B, et al. De Utrechtse Coping Lijst: UCL. Omgaan met problemen en gebeurtenissen. (The Utrecht coping questionnaire. Coping with problems and life events). Lisse: Swets and Zeitlinger, 1988.

20 Halfens RJG. Locus of control: beheersingsorientatie in relatie tot ziekte: en gezondheidsgedrag. (Locus of control in relation to sickness and health behaviour). Maastricht: Rijksuniversiteit Limburg, 1985.

21 Deyo RA. Comparative validity of the sickness impact profile and shorter scales for functional assessment in low back pain. Spine 1986;11:951-4.

22 Stratford PW, Binkley J, Solomon P, et al. Assessing change over time in patients with low back pain. Phys Ther 1994;74:528-33.

23 Cohen G, Forbes J, Garraway M. Can different patient satisfaction survey methods yield consistent results? Comparison of three surveys. BMF 1996;313:841-4.

24 Greenfield S, Cretin S, Worthman LG, et al. Comparison of a criteria map to a criteria list in quality of care assessment for patients with chest pain: the relation of each to outcome. Medical Care 1981;19:255-72.

25 Greenfield S, Lewis CE, Kaplan SH, et al. Peer review by criteria mapping: criteria for diabetes mellitus. The use of decision-making in chart audit. Ann Intern Med 1975;83: 761-70.

26 Palmer RH, Strain R, Maurer JV, et al. A method for evaluting performance of ambulatory pediatric tasks. Pediatrics 1984;73:269-77

27 Van Amstel RJ, Buijs PC. Voor verbetering vatbaar. De samenwerking tussen huisarts en bedrijfsarts bij sociaal-medische begeleiding (Guidance of sickness absence: co-operation of occupational physician and general practitioner). Amsterdam: tional physician

28 De Bono AM. Communication between an occupational physician and other medical practitioners: an audit. Occup physician and other mec

29 Nederlandse Vereniging voor Arbeids: en Bedrijfsgeneeskunde. Convenant LHV-NVAB. (Agreement National Association of General Practitioners: Dutch Association of Occupational Physicians). Tijdschrift voor Bedrijfsen Verzekeringsgeneeskunde 1997;5:162-3.

30 Vlaeyen JW, Kole-Snijders AM, Boeren RG, et al. Fear of movement/(re)injury in chronic low-back pain and its relation to behavioral performance. Pain 1995;62:363-72.

31 Terluin B. Overspanning onderbouwd. (A basis for surmenage.) [Academic thesis]. Utrecht: University of Utrecht, 1994.

32 Beissner KL, Saunders RL, McManis BG. Factors related to successful work hardening outcomes. Phys Ther 1996;76: $1188-201$.

33 Hazard RG, Haugh LD, Green PA, et al. Chronic low back pain: the relationship between patient satisfaction and pain, impairment, and disability outcomes. Spine 1994;19:8817.

34 Bosma YR, Verbeek JHAM, Van der Weide WE, Salle HJA. Satisfactie van werknemers en bedrijfsartsen met het verzuimconsult. (Satisfaction of employees and occupational physicians with consultation for sickness absence). Tijdschrift voor Bedrijfs en Verzekeringsgeneeskunde 1996;4: $42-8$ 